BMJ Open

Sport \&

Exercise

Medicine

\title{
Early repolarisation among athletes
}

Femke M A P Claessen (D) ,' Heidi A P Peeters, ${ }^{2}$ Bastiaan J Sorgdrager, ${ }^{3}$ Peter $\mathrm{L} J$ van Veldhoven ${ }^{1}$

To cite: Claessen FMAP, Peeters HAP, Sorgdrager BJ, et al. Early repolarisation among athletes. BMJ Open Sport \& Exercise Medicine 2020;6:e00694. doi:10.1136/ bmjsem-2019-000694

- Additional material is published online only. To view please visit the journal online (http://dx.doi.org/10.1136/ bmjsem-2019-000694).

Accepted 14 February 2020

Check for updates

C) Author(s) (or their employer(s)) 2020. Re-use permitted under CC BY-NC. No commercial re-use. See rights and permissions. Published by BMJ.

${ }^{1}$ Sports Medicine, Medisch Centrum Haaglanden, Leidschendam, Zuid-Holland, Netherlands

${ }^{2}$ Cardiology, Medisch Centrum Haaglanden, Leidschendam, Zuid-Holland, Netherlands ${ }^{3}$ Cardiology, Medisch Centrum Haaglanden, Den Haag, ZuidHolland, Netherlands

Correspondence to Dr Femke M A P Claessen; femke_claessen@hotmail.com

\section{ABSTRACT}

Objectives Traditionally, early repolarisation (ER) is considered a benign ECG variant, predominantly found in youths and athletes. However, a limited number of studies have reported an association between ER and the incidental occurrence of ventricular fibrillation or sudden cardiac death. Yet definite, direct comparisons of the incidence of ER in unselected, contemporary populations in athletes as compared with non-athletes and across different sports are lacking. This study therefore aimed to investigate whether ER is more common among athletes as compared with non-athletes, and if ER patterns differ between sport disciplines based on static and dynamic intensity.

Methods To assess ER we retrospectively analysed ECGs of 2241 adult subjects (2090 athletes, 151 non-athletes), who had a sports medical screening between 2010 and 2014 in an outpatient clinic. The outcome was tested for confounders in a multivariable logistic regression analysis. Results ER was found in 502 athletes (24\%). We found a $50 \%$ higher prevalence of ER in the athlete group compared with the control group (OR 1.5 (SE 0.34), adjusted $95 \% \mathrm{Cl} 1.0$ to 2.4 ) in multivariable analysis. A $30 \%$ higher prevalence of ER in the inferior leads only (OR 1.3 (SE 0.38), adjusted $95 \% \mathrm{Cl} 0.74$ to 2.3 ), a $120 \%$ higher prevalence of ER in the lateral leads only (OR 2.2 (SE 1.0), adjusted $95 \% \mathrm{Cl} 0.87$ to 5.4 ), and a $20 \%$ higher prevalence of ER in the inferior and lateral leads (OR 1.2 (SE 0.49), adjusted $95 \% \mathrm{Cl} 0.55$ to 2.7 ) was found in athletes. Conclusion Athletes had a $50 \%$ higher prevalence of ER and a $30 \%$ higher prevalence of ER in the inferior leads specifically. There was no association between training duration or sports discipline and ER.

\section{INTRODUCTION}

Early repolarisation (ER) is common on ECGs in the general population. ${ }^{1-3}$ ER consists of J-wave notching or slurring on the downslope of an R-wave. ${ }^{4}$ It can present with an ascending ST segment and a descending or horizontal ST segment (figure 1).

Historically, ER has been considered a benign ECG variant that predominates in youths and athletes and Afro-Americans. However, recently this belief has been challenged. ${ }^{156}$ Several studies found an association between specific ER patterns and incidental life-threatening arrhythmias or sudden cardiac death. ${ }^{15}$ 7-10

\section{What are the new findings?}

Athletes have a $50 \%$ higher prevalence of early repolarisation (ER)

- There is a $30 \%$ higher prevalence of ER in the inferior leads specifically in athletes.

- There was no association between ER and training duration or sports discipline.

The ST segment morphology was found to distinguish high-risk patterns from benign patterns. ${ }^{9}$ The occurrence of a J-point amplitude higher than $0.2 \mathrm{mV}$ in multiple leads, particularly the inferior leads, was shown to increase the risk of arrhythmias and sudden cardiac death. ${ }^{11} 12$ Evidence accumulates that subjects with ER in the inferior leads, with a horizontal or descending ST segment, have the highest risk for arrhythmias and sudden cardiac death. ${ }^{4512-14}$

Higher prevalence of both malignant and benign ER patterns on ECGs immediately after intense exercise training in competitive endurance athletes was shown. ${ }^{6}$ A subsequent study showed that the ER pattern disappeared in $>50 \%$ of the healthy elite athletes after detraining. ${ }^{15}$ This suggests that ER is a dynamic phenomenon related to the magnitude of physical activity.

An unresolved question is whether the prevalence of ER differs between sport disciplines and their intensity. The aim of this study is to investigate if ER is more common among athletes as compared with non-athletes. As a secondary aim, we compared ER patterns between sport disciplines based on static and dynamic intensity.

\section{METHODS}

\section{Patient and public involvement}

Patients and/or the public were not involved in the design, or conduct, or reporting, or dissemination plans of this research.

\section{Participants}

We identified 3006 adult subjects that visited the sports medical department at the Haaglanden Medical Center in the Netherlands between 2010 and 2014 for a sports 

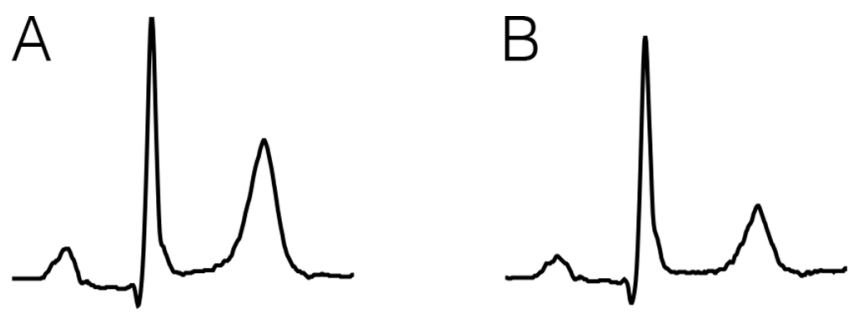

Figure 1 Early repolarisation pattern. (A) Slurred J point with ascending ST segment. (B) Slurred J point with horizontal ST segment.

medical screening. Subjects with active cancer or history of chemotherapy $(n=407)$, unknown duration of sports $(n=199)$, diabetes mellitus $(n=44)$, unknown ethnicity $(n=9)$ and chronic obstructive pulmonary disease $(n=5)$ were excluded. After excluding patients with diabetes and history of active cancer or chemotherapy, there were no dialysis patients and no patients with a history of cardiovascular disease in the remaining cohort. Of the remaining 2342 subjects, we reviewed the ECGs that were obtained during the sports medical screening for ER. Subjects in the control group had the same sports medical screening, mainly for occupational purposes. They did not perform any sports. The exclusion criteria were identical to the athlete group.

Subjects with QRS duration $\geq 120 \mathrm{~ms}(\mathrm{n}=80)$, myocardial infarction pattern on ECG, defined by pathological q-waves or repolarisation abnormalities that are suggestive of a history of myocardial infarction $(n=10)$, no rest ECG $(n=5)$, poor ECG quality $(n=5)$ and pre-excitation $(n=1)$, were also excluded from analysis. There were no subjects with epsilon waves in V1-V3 or Brugada criteria. In total, 2241 subjects were included (online supplementary appendix 1).

\section{Definition of ER}

We used the definition of Macfarlane et al for ER: "Early repolarization is present if all of the following criteria are met. 1. There is an end-QRS notch or slur on the downslope of a prominent R-wave. If there is a notch, it should lie entirely above the baseline. 2 . Jp is $\geq 0.1 \mathrm{mV}$ in two or more contiguous leads of the 12-lead ECG, excluding leads V1 to V3. 3. QRS duration is $<120 \mathrm{ms"4}$ (figure 2).

\section{ECG evaluation}

All identifiable information was removed from the ECGs by a research fellow who was not further involved in the study. An ECG in supine position in resting condition was used to assess ER. One independent researcher who was trained in ECG evaluation (resident Sports Medicine) evaluated the ECGs.

If there was doubt about the presence of ER a second researcher (cardiac electrophysiologist) evaluated the ECG and a consensus was reached.

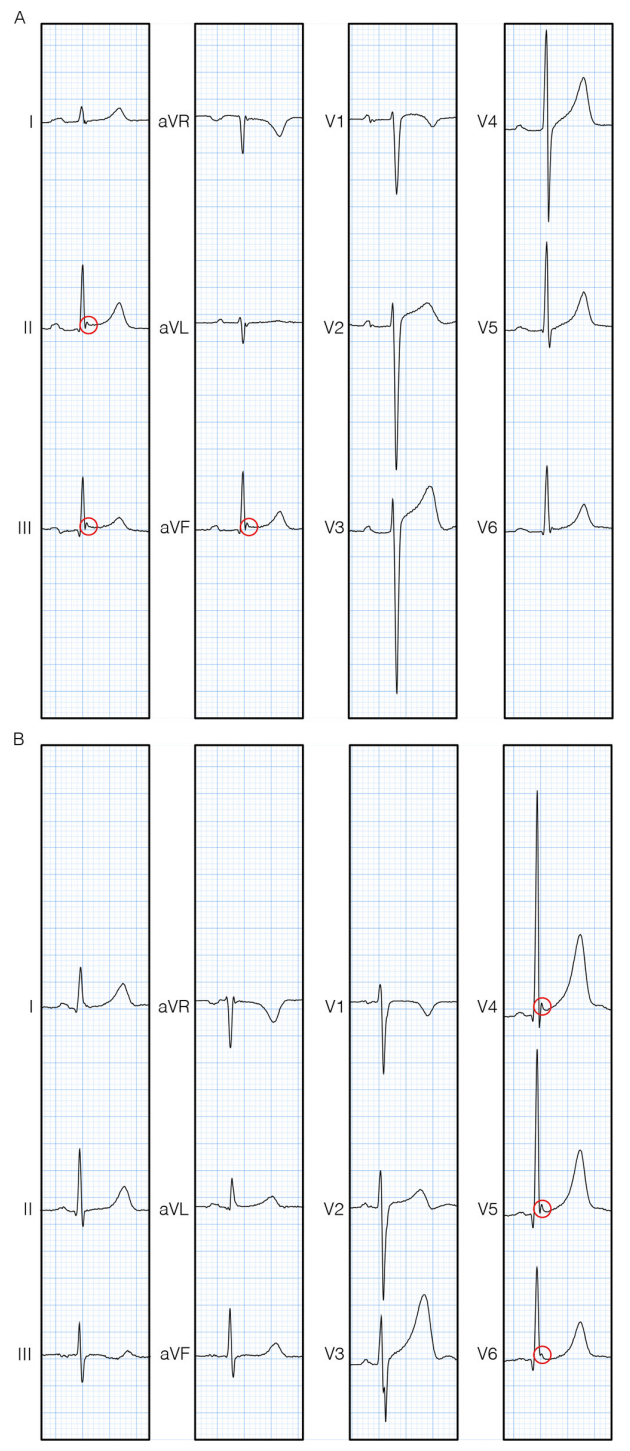

Figure 2 Subjects with early repolarisation. (A) Subject with early repolarisation in the inferior leads only. (B) Subject with early repolarisation in the lateral leads only.

\section{Explanatory variables}

Subject charts were reviewed for characteristics such as age, sex, ethnicity (Caucasian, black, other), sport disciplines based on static and dynamic intensity, duration of training $(<150 \mathrm{~min}$ per week, $150-300 \mathrm{~min}$ per week, $>300$ min per week) and sudden cardiac death in firstdegree family (table 1 ).

Levine et al developed a classification model of sports based on peak static and dynamic components; a modified Mitchell's classification. ${ }^{16}$ We used this classification to categorise sport disciplines (figure 3).

If subjects participated in multiple sport disciplines, we included them in multiple categories, except for subjects who participated in one sport discipline for more than $50 \%$ of time. For analysis, we grouped the subjects into category A, B, C or multiple and 1, 2, 3 or multiple since the number of subjects in some subcategories was too small for analysis. We also compared group A (low dynamic exercise) with group $\mathrm{C}$ (high dynamic exercise) 
Table 1 Patient characteristics

\begin{tabular}{|c|c|c|c|c|c|}
\hline Patient characteristic & $\begin{array}{l}\text { All patients } \\
(\mathrm{n}=2241)\end{array}$ & $\begin{array}{l}\text { Sport duration } \\
<150 \mathrm{~min} / \text { week } \\
(\mathrm{n}=423)\end{array}$ & $\begin{array}{l}\text { Sport duration } \\
150-300 \mathrm{~min} / \text { week } \\
(\mathrm{n}=716)\end{array}$ & $\begin{array}{l}\text { Sport duration } \\
>300 \mathrm{~min} / \text { week } \\
(\mathrm{n}=951)\end{array}$ & $\begin{array}{l}\text { Control group/ } \\
\text { no sports } \\
\text { activity } \\
(\mathrm{n}=151)\end{array}$ \\
\hline Age, mean (SD), years & $42(15)$ & $47(12)$ & $46(13)$ & $37(16)$ & 47 (12) \\
\hline \multicolumn{6}{|l|}{ Sex, n (\%) } \\
\hline Male & $1593(71)$ & $257(61)$ & $494(69)$ & $751(79)$ & $91(60)$ \\
\hline Female & $648(29)$ & $166(39)$ & $222(31)$ & $200(21)$ & $60(40)$ \\
\hline \multicolumn{6}{|l|}{ Ethnicity, n (\%) } \\
\hline Caucasian & 2045 (91) & $391(92)$ & $679(95)$ & $851(89)$ & $124(82)$ \\
\hline Black & $155(7)$ & $21(5)$ & $29(4)$ & $84(9)$ & $21(14)$ \\
\hline Other & $41(2)$ & $11(3)$ & $8(1)$ & $16(2)$ & $6(4)$ \\
\hline \multicolumn{6}{|l|}{$\begin{array}{l}\text { Sudden cardiac death in } \\
\text { first-degree family, } \mathrm{n}(\%)\end{array}$} \\
\hline Yes & $16(1)$ & $5(1)$ & $8(1)$ & $3(<1)$ & $0(0)$ \\
\hline No & 2225 (99) & 418 (99) & 708 (99) & $948(100)$ & $0(0)$ \\
\hline \multicolumn{6}{|l|}{ Sports discipline, n (\%) } \\
\hline A1 & $13(1)$ & $5(1)$ & $2(<1)$ & $6(1)$ & \\
\hline A2 & $8(<1)$ & $3(1)$ & $4(1)$ & $1(<1)$ & \\
\hline A3 & $265(13)$ & $92(22)$ & $79(11)$ & $94(10)$ & \\
\hline B1 & $10(<1)$ & $3(1)$ & $1(<1)$ & $6(1)$ & \\
\hline B2 & $4(<1)$ & $0(0)$ & $1(<1)$ & $3(<1)$ & \\
\hline B3 & $1(<1)$ & $0(0)$ & $0(0)$ & $1(<1)$ & \\
\hline C1 & $230(11)$ & $27(6)$ & $39(5)$ & $164(17)$ & \\
\hline C2 & 356 (17) & $141(33)$ & $142(20)$ & $73(8)$ & \\
\hline $\mathrm{C} 3$ & $516(25)$ & 67 (16) & $164(23)$ & $285(30)$ & \\
\hline Multiple & 687 (33) & $85(20)$ & $285(40)$ & 318 (33) & \\
\hline
\end{tabular}

Early repolarisation was found in 502 athletes (24\%) and in 26 non-athletes (17\%).

and group 1 (low static exercise) with group 3 (high static exercise).

\section{Statistical analysis}

Subject characteristics were described using frequencies and percentages. Linearity of the variables was tested with supply regression curves. A univariate analysis was performed to test if there was an association between ER and sports participation. A univariate analysis was also performed to compare the prevalence of ER in subjects with low dynamic exercise versus high dynamic exercise and low static exercise versus high static exercise.

The outcome was tested for confounders (age, sex and ethnicity) in a multivariable logistic regression analysis.

\section{RESULTS}

Of the 2241 included subjects 2090 (93\%) were athletes. ER was found in 502 athletes (24\%) and in 26 non-athletes $(17 \%)$. Detailed subject characteristics are described in table 1 . In total, the athlete group had a $50 \%$ higher prevalence of ER compared with the control group (OR 1.5 (SE 0.34), adjusted 95\% CI 1.0 to 2.4) (table 2).
Agreement among observers regarding the ECG evaluation was calculated for 50 subjects using a multirater kappa. ${ }^{17}$ Zero indicates no agreement beyond what was expected attributable to chance alone. A value of 0.01 to 0.20 indicates poor agreement, 0.21 to 0.40 fair agreement, 0.41 to 0.60 moderate agreement, 0.61 to 0.80 substantial agreement, and more than 0.81 almost perfect agreement. We found a kappa of 0.86 between the first and second researcher, indicating the highest category of agreement.

After testing for confounders such as age, sex and ethnicity, the OR remains 1.5, implying that the higher prevalence of ER is independent of the tested (possible) confounders (table 3; online supplementary appendix 2).

A 30\% higher prevalence of ER in the inferior leads only (OR 1.3 (SE 0.38), adjusted 95\% CI 0.74 to 2.3) was found in the athlete group compared with the control group after testing for confounders (table 3; online supplementary appendix 2), a 120\% higher prevalence of ER in the lateral leads only (OR 2.2 (SE 1.0), adjusted 95\% CI 0.87 


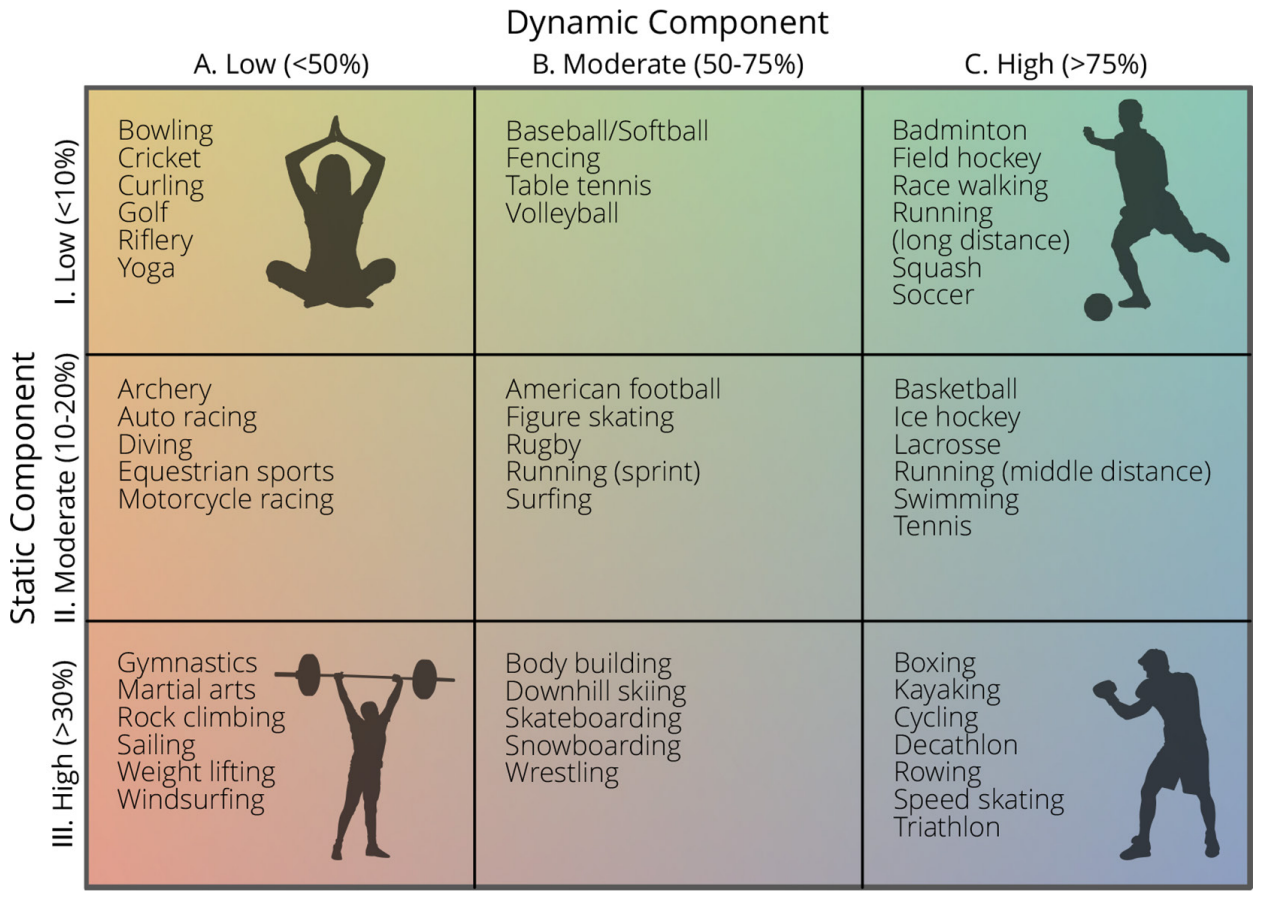

Figure 3 Model of sports based on the Levine classification. Classification based on peak static and dynamic components.

to 5.4) (table 3; online supplementary appendix 2), and a $20 \%$ higher prevalence of ER in both the inferior and lateral leads (OR 1.2 (SE 0.49), adjusted 95\% CI 0.55 to 2.7) was found in the athletes group compared with the control group after testing for confounders (table 3; online supplementary appendix 2).

No clear association was found between training duration and ER (table 2). Also, no association between ER and sport disciplines, based on static and dynamic intensity, was found (table 2). If we compared the effect of dynamic sports discipline versus static sports discipline versus a combination of dynamic and static sports discipline on ER, there was no difference.

In the subgroup analysis, we observed a higher prevalence of ER in both the lateral and inferior leads and in the lateral leads only in the black ethnicity after testing for confounders (table 3; online supplementary appendix 2). There was no association between black ethnicity and ER in the inferior leads only.

Only 16 subjects $(1 \%)$ in our cohort had occurrence of sudden cardiac death in their first-degree family. Because of this small group size, it was not possible to assess this variable in a multivariable logistic regression analysis. However, the ECGs of these 16 subjects did not show any abnormalities. After a follow-up period of at least 3 years, none of the subjects have died.

\section{DISCUSSION}

In our study, we found a $50 \%$ higher prevalence of ER in the athlete group compared with the control group (non-athletes) after testing for confounders. Athletes had a $30 \%$ higher prevalence of ER in the inferior leads specifically, and we found no association between training duration or sports discipline and ER.

\section{ER and sports participation}

It is described in literature that ER is more common in athletes. $^{2} 18$ This agrees with the conclusion of this study. However, earlier studies did not test for all possible confounding factors, such as age, sex and ethnicity. Noseworthy et al showed that the prevalence of ER on ECG before and after training among endurance athletes increased significantly. ${ }^{6}$ They found no increase of ER in strength athletes, such as American football players. These results imply that ER is more likely to occur after endurance training than following strength training. However, we did not find an association between ER and sport disciplines based on static and dynamic intensity. So, there might be no association between ER and training duration or sports discipline. It is also possible that there is a sports participation recall or reporting bias. With the rise of smart watches, it will be easier to assess training duration per week in future studies.

\section{Aetiology of ER}

We found a higher prevalence of some types of ER among black athletes. Earlier studies also reported the highest prevalence of ER in African-Americans. ${ }^{19} \mathrm{We}$ found a higher prevalence of some types of ER among black athletes. Earlier studies also described the highest prevalence of ER in African-Americans. Hispanics have been found to have a prevalence of ER somewhere between that of African and Caucasian ethnicities. Gussak and Antzelevitch described similarities between the underlying cellular and ionic mechanisms of Brugada syndrome and ER. This might indicate that under certain conditions, the arrythmia risk in patients with ER can increase. ${ }^{20}$ Several studies describe different mechanisms for the emergence of ER and the exact aetiology remains 
Table 2 Univariate analysis early repolarisation

\begin{tabular}{|c|c|c|c|}
\hline \multicolumn{4}{|c|}{ A. All patients with early repolarisation } \\
\hline Parameter & OR (SE) & $95 \% \mathrm{Cl}$ & $P$ value \\
\hline Age & $1.0(0.0034)$ & 0.99 to 1.0 & 0.75 \\
\hline \multicolumn{4}{|l|}{ Sex } \\
\hline Male $(n=1593)$ & Reference group & & \\
\hline Female $(n=648)$ & $1.2(0.14)$ & 0.97 to 1.5 & 0.091 \\
\hline \multicolumn{4}{|l|}{ Ethnicity } \\
\hline Caucasian $(n=2045)$ & Reference group & & \\
\hline Black $(n=155)$ & $1.3(0.26)$ & 0.97 to 2.0 & 0.070 \\
\hline Other $(n=41)$ & $0.57(0.016)$ & 0.24 to 1.4 & 0.20 \\
\hline \multicolumn{4}{|l|}{ Sports participation } \\
\hline No $(n=151)$ & Reference group & & \\
\hline Yes $(n=2090)$ & $1.5(0.34)$ & 0.98 to 2.3 & 0.060 \\
\hline
\end{tabular}

Duration of training per

week

\begin{tabular}{|c|c|c|c|}
\hline$<150 \min (n=423)$ & Reference group & & \\
\hline $150-300 \min (n=716)$ & $1.0(0.14)$ & 0.76 to 1.3 & 0.96 \\
\hline$>300 \min (n=951)$ & $0.93(1.3)$ & 0.71 to 1.2 & 0.56 \\
\hline \multicolumn{4}{|c|}{ Sports discipline dynamic component } \\
\hline$A(n=286)$ & Reference group & & \\
\hline$C(n=1102)$ & $0.92(0.14)$ & 0.68 to 1.2 & 0.58 \\
\hline \multicolumn{4}{|c|}{ Sports discipline static component } \\
\hline $1(n=253)$ & Reference group & & \\
\hline $3(n=782)$ & $1.0(0.17)$ & 0.73 to 1.4 & 0.92 \\
\hline
\end{tabular}

Sports discipline dynamic vs static vs combination

$\begin{array}{llll}\text { A3 }(n=265) & \text { Reference group } & & \\ \text { C1 }(n=230) & 0.94(0.19) & 0.62 \text { to } 1.4 & 0.75 \\ \text { C3 }(n=516) & 0.91(0.16) & 0.65 \text { to } 1.3 & 0.58\end{array}$

Sports discipline dynamic vs static

$\begin{array}{llll}\text { A3+B3 }(n=266) & \text { Reference group } & & \\ \text { C1+C2 }(n=586) & 0.88(0.15) & 0.63 \text { to } 1.2 & 0.45\end{array}$

B. All patients with early repolarisation in inferior leads only

\begin{tabular}{|c|c|c|c|}
\hline Age & $1.0(0.0044)$ & 0.99 to 1.0 & 0.37 \\
\hline \multicolumn{4}{|l|}{ Gender } \\
\hline Male $(n=1407)$ & Reference group & & \\
\hline Female $(n=580)$ & $1.2(0.18)$ & 0.93 to 1.7 & 0.15 \\
\hline \multicolumn{4}{|l|}{ Ethnicity } \\
\hline Caucasian (n=1822) & Reference group & & \\
\hline Black $(n=127)$ & $0.93(0.24)$ & 0.56 to 1.5 & 0.78 \\
\hline Other $(n=38)$ & $0.56(0.34)$ & 0.17 to 1.8 & 0.34 \\
\hline \multicolumn{4}{|l|}{ Sports participation } \\
\hline No $(n=139)$ & Reference group & & \\
\hline Yes $(n=1848)$ & $1.4(0.40)$ & 0.79 to 2.4 & 0.25 \\
\hline \multicolumn{4}{|l|}{$\begin{array}{l}\text { Duration of training per } \\
\text { week }\end{array}$} \\
\hline$<150 \min (n=361)$ & Reference group & & \\
\hline $150-300 \min (n=636)$ & $1.4(0.28)$ & 0.98 to 2.1 & 0.063 \\
\hline$>300 \min (n=851)$ & $1.3(0.25)$ & 0.90 to 1.9 & 0.16 \\
\hline
\end{tabular}

Continued
Table 2 Continued

C. All patients with early repolarisation in lateral leads only

\begin{tabular}{|c|c|c|c|}
\hline Age & $1.0(0.0059)$ & 1.0 to 1.0 & 0.20 \\
\hline \multicolumn{4}{|l|}{ Gender } \\
\hline Male $(n=1315)$ & Reference group & & \\
\hline Female $(n=542)$ & $1.5(0.32)$ & 1.0 to 2.3 & 0.045 \\
\hline \multicolumn{4}{|l|}{ Ethnicity } \\
\hline Caucasian $(n=1696)$ & Reference group & & \\
\hline Black $(n=125)$ & $1.7(0.49)$ & 1.0 to 3.0 & 0.048 \\
\hline Other $(n=36)$ & $0.38(0.38)$ & 0.051 to 2.8 & 0.34 \\
\hline \multicolumn{4}{|l|}{ Sports participation } \\
\hline No $(n=130)$ & Reference group & & \\
\hline Yes $(n=1727)$ & $2.1(0.96)$ & 0.84 to 5.2 & 0.11 \\
\hline
\end{tabular}

Duration of training per

week

\begin{tabular}{|c|c|c|c|}
\hline$<150 \min (n=353)$ & Reference group & & \\
\hline $150-300 \min (n=583)$ & $0.77(0.18)$ & 0.48 to 1.2 & 0.26 \\
\hline$>300 \min (n=791)$ & $0.77(0.17)$ & 0.50 to 1.2 & 0.24 \\
\hline \multicolumn{4}{|c|}{$\begin{array}{l}\text { D. All patients with early repolarisation in inferior and lateral } \\
\text { leads }\end{array}$} \\
\hline Age & $1.0(0.0067)$ & 0.99 to 1.0 & 0.50 \\
\hline \multicolumn{4}{|l|}{ Gender } \\
\hline Male $(n=1275)$ & Reference group & & \\
\hline Female $(n=548)$ & $0.79(0.16)$ & 0.53 to 1.2 & 0.26 \\
\hline \multicolumn{4}{|l|}{ Ethnicity } \\
\hline Caucasian $(n=1665)$ & Reference group & & \\
\hline Black $(n=121)$ & $1.7(0.54)$ & 0.91 to 3.2 & 0.094 \\
\hline Other $(n=37)$ & $1.0(0.76)$ & 0.25 to 4.4 & 0.96 \\
\hline \multicolumn{4}{|l|}{ Sports participation } \\
\hline No $(n=132)$ & Reference group & & \\
\hline Yes (n=1692) & $1.1(0.43)$ & 0.49 to 2.3 & 0.87 \\
\hline \multicolumn{4}{|l|}{$\begin{array}{l}\text { Duration of training per } \\
\text { week }\end{array}$} \\
\hline$<150 \min (n=347)$ & Reference group & & \\
\hline $150-300 \min (n=573)$ & $0.73(0.19)$ & 0.43 to 1.2 & 0.22 \\
\hline$>300 \min (n=771)$ & $0.62(0.16)$ & 0.38 to 1.0 & 0.059 \\
\hline
\end{tabular}

unclear. A multifactorial origin for the development of ER is most likely.

\section{ER and sudden cardiac death}

Recently, it was found that some types of ER might be malignant. ${ }^{4}{ }^{12-14}$ However, Cappato et al showed no recurrent ventricular arrhythmias in athletes who had suffered a cardiac arrest, after discontinuation of sports for 3 years, despite persistent ER on their ECG. ${ }^{14}$ Therefore, it might be possible that ventricular arrhythmias in subjects with ER on their ECG are triggered by repeated exercise instead of ER. Alternatively, the trigger could be a combination of certain subtypes of ER and repeated exercise.

Despite the higher prevalence of ER in athletes, the absolute risk for ventricular fibrillation remains low. 
Table 3 Multivariable analysis early repolarisation

\begin{tabular}{llll}
\hline \multicolumn{4}{l}{ A. All patients with early repolarisation } \\
\hline Parameter & OR (SE) & $\begin{array}{l}\text { Adjusted 95\% } \\
\text { Cl }\end{array}$ & $\begin{array}{l}\text { Adjusted P } \\
\text { value }\end{array}$ \\
\hline $\begin{array}{l}\text { Sports participation } \\
\text { Ethnicity }\end{array}$ & $1.5(0.34)$ & 1.0 to 2.4 & 0.053 \\
\hline \multicolumn{1}{c}{ Caucasian } & $\begin{array}{l}\text { Reference } \\
\text { group }\end{array}$ & \\
\hline \multicolumn{1}{c}{ Black } & $1.5(0.28)$ & 1.0 to 2.1 & 0.042 \\
\hline Other & $0.60(0.27)$ & 0.25 to 1.5 & 0.26 \\
Sex & $1.2(0.13)$ & 0.94 to 1.5 & 0.16 \\
\hline Age & $1.0(0.0035)$ & 1.0 to 1.0 & 0.45 \\
\hline
\end{tabular}

B. All patients with early repolarisation in inferior leads only

Sports participation $1.3(0.38) \quad 0.74$ to $2.3 \quad 0.36$

Ethnicity

\begin{tabular}{clll} 
Caucasian & $\begin{array}{l}\text { Reference } \\
\text { group }\end{array}$ & & \\
\hline Black & $0.89(0.24)$ & 0.53 to 1.5 & 0.65 \\
\hline Other & $0.58(0.35)$ & 0.18 to 1.9 & 0.36 \\
\hline Sex & $1.2(0.18)$ & 0.92 to 1.7 & 0.15 \\
\hline Age & $1.0(0.0045)$ & 0.99 to 1.0 & 0.32 \\
\hline
\end{tabular}

C. All patients with early repolarisation in lateral leads only

Sports participation $2.2(1.0) \quad 0.89$ to $5.6 \quad 0.086$

Ethnicity

\begin{tabular}{llll} 
Caucasian & $\begin{array}{l}\text { Reference } \\
\text { group }\end{array}$ & & \\
\hline Black & $2.0(0.60)$ & 1.2 to 3.6 & 0.015 \\
\hline Other & $0.44(0.44)$ & 0.059 to 3.2 & 0.42 \\
\hline Sex & $1.4(0.30)$ & 0.95 to 2.2 & 0.089 \\
\hline Age & $1.0(0.0062)$ & 1.0 to 1.0 & 0.077 \\
\hline
\end{tabular}

D. All patients with early repolarisation in inferior and lateral leads

\begin{tabular}{llll}
\hline $\begin{array}{l}\text { Sports participation } \\
\text { Ethnicity } \\
\text { Caucasian }\end{array}$ & $\begin{array}{l}\text { Reference } \\
\text { group }\end{array}$ & 0.55 to 2.7 & 0.63 \\
\hline Black & $1.9(0.63)$ & 1.0 to 3.7 & 0.049 \\
Other & $1.0(0.77)$ & 0.25 to 4.4 & 0.95 \\
Sex & $0.77(0.16)$ & 0.51 to 1.2 & 0.20 \\
\hline Age & $1.0(0.0070)$ & 1.0 to 1.0 & 0.25 \\
\hline
\end{tabular}

Rosso et al found an absolute risk of 30 per 100000 for idiopathic ventricular fibrillation in subjects with inferolateral $\mathrm{J}$ waves and a horizontal or downsloping ST segment. ${ }^{12}$

\section{Management of subjects with ER}

Increased popularity of sports medical screening will increase the detection of ER in athletes and nonathletes. However, for almost all of these subjects, the absolute risk for ventricular fibrillation and sudden cardiac death is very low. Moreover, robust evidence for a relation between (subtypes of) ER and sudden cardiac death is lacking. Therefore, we suggest that as long as there are no other factors that increase the risk of sudden cardiac death (such as sudden cardiac death in first-degree family), there is no reason to perform follow-up intervention in these subjects. This is of course until accurate diagnostic tools and risk stratification models are available.

\section{Limitations}

This study should also be viewed in light of its limitations. First, age, ethnicity, and sex differed in the athlete and control groups. To account for this, we adjusted the outcome for these confounders in a multivariable analysis. Second, the numbers per category classified according the Levine classification model of sports based on peak static and dynamic components were too small for subgroup analysis. Third, no data were available on antihypertensive medication. Finally, this study design is retrospective, which makes it inherently more susceptible to data loss, bias and confounding than a prospective study design.

\section{CONCLUSION}

Athletes have a $50 \%$ higher prevalence of ER and a $30 \%$ higher prevalence of ER in the inferior leads specifically. We found no association between training duration or sports discipline and ER. Future studies should focus on the aetiological factors of ER and risk stratification models should be developed to gain clarity on the remaining questions regarding ER.

Acknowledgements The authors would like to thank Debbie Timmermans for removing all identifiable information from the ECGs.

Contributors All authors wrote the research protocol and manuscript. FC and HP reviewed the ECGs and FC analysed the data.

Funding The authors have not declared a specific grant for this research from any funding agency in the public, commercial or not-for-profit sectors.

Competing interests None declared.

Patient consent for publication Not required.

Ethics approval This retrospective study was approved by the institutional medical ethical review board (METC 18-070).

Provenance and peer review Not commissioned; externally peer reviewed.

Data availability statement All data relevant to the study are included in the article or uploaded as online supplementary information.

Open access This is an open access article distributed in accordance with the Creative Commons Attribution Non Commercial (CC BY-NC 4.0) license, which permits others to distribute, remix, adapt, build upon this work non-commercially, and license their derivative works on different terms, provided the original work is properly cited, appropriate credit is given, any changes made indicated, and the use is non-commercial. See: http://creativecommons.org/licenses/by-nc/4.0/.

ORCID iD

Femke M A P Claessen http://orcid.org/0000-0003-0778-850X

\section{REFERENCES}

1 Sharma S, Drezner JA, Baggish A, et al. International recommendations for electrocardiographic interpretation in Athletes. J Am Coll Cardiol 2017;69:1057-75.

2 Klatsky AL, Oehm R, Cooper RA, et al. The early repolarization normal variant electrocardiogram: correlates and consequences. Am J Med 2003;115:171-7. 
3 Mehta M, Jain AC, Mehta A. Early repolarization. Clin Cardiol 1999;22:59-65.

4 Macfarlane PW, Antzelevitch C, Haissaguerre M, et al. The early repolarization pattern: a consensus paper. J Am Coll Cardiol 2015;66:470-7.

5 Haïssaguerre M, Derval N, Sacher F, et al. Sudden cardiac arrest associated with early repolarization. $N$ Engl $\mathrm{J} \mathrm{Med}$ 2008;358:2016-23.

6 Noseworthy PA, Tikkanen JT, Porthan K, et al. The early repolarization pattern in the general population: clinical correlates and heritability. J Am Coll Cardiol 2011;57:2284-9.

7 Rosso R, Kogan E, Belhassen B, et al. J-point elevation in survivors of primary ventricular fibrillation and matched control subjects: incidence and clinical significance. J Am Coll Cardiol 2008;52:1231-8.

8 Tikkanen JT, Anttonen O, Junttila MJ, et al. Long-term outcome associated with early repolarization on electrocardiography. $N$ Engl $J$ Med 2009;361:2529-37.

9 Tikkanen JT, Huikuri HV. Characteristics of "malignant" vs. "benign" electrocardiographic patterns of early repolarization. J Electrocardiol 2015;48:390-4.

10 Sinner MF, Reinhard W, Müller M, et al. Association of early repolarization pattern on ECG with risk of cardiac and all-cause mortality: a population-based prospective cohort study (MONICA KORA). PLoS Med 2010;7:e1000314.

11 Tikkanen JT, Junttila MJ, Anttonen O, et al. Early repolarization: electrocardiographic phenotypes associated with favorable longterm outcome. Circulation 2011;123:2666-73.
12 Rosso R, Glikson E, Belhassen B, et al. Distinguishing "benign" from "malignant early repolarization": the value of the ST-segment morphology. Heart Rhythm 2012;9:225-9.

13 Tikkanen JT, Wichmann V, Junttila MJ, et al. Association of early repolarization and sudden cardiac death during an acute coronary event. Circ Arrhythm Electrophysiol 2012;5:714-8.

14 Cappato R, Furlanello F, Giovinazzo V, et al. J wave, QRS slurring, and ST elevation in athletes with cardiac arrest in the absence of heart disease: marker of risk or innocent bystander? Circ Arrhythm Electrophysiol 2010;3:305-11.

15 Serra-Grima R, Doñate M, Álvarez-García J, et al. Long-term follow-up of early repolarization pattern in elite athletes. Am J Med 2015:128:192 e1-192 e9.

16 Levine BD, Baggish AL, Kovacs RJ, et al. Eligibility and disqualification recommendations for competitive athletes with cardiovascular abnormalities: Task force 1: classification of sports: dynamic, static, and impact: a scientific statement from the American Heart Association and American College of Cardiology. $J$ Am Coll Cardiol 2015;66:2350-5.

17 Landis JR, Koch GG. The measurement of observer agreement for categorical data. Biometrics 1977;33:159-74.

18 Bianco M, Bria S, Gianfelici A, et al. Does early repolarization in the athlete have analogies with the Brugada syndrome? Eur Heart $J$ 2001;22:504-10.

19 Aagaard P, Shulman E, Di Biase L, et al. Prognostic value of automatically detected early repolarization. Am J Cardiol 2014;114:1431-6.

20 Gussak I, Antzelevitch C. Early repolarization syndrome: clinical characteristics and possible cellular and ionic mechanisms. $J$ Electrocardiol 2000;33:299-309. 